\title{
Immune Modulatory Effects of Hypercholesterolemia: Can Atorvastatin Convert the Detrimental Effect of Hypercholesterolemia on the Immune System?
}

\author{
Zeinab Emruzi ${ }^{1}$, Pegah Babaheidarian ${ }^{2}$ and Ghasem Ahangari ${ }^{1^{*}}$ \\ ${ }^{1}$ Department of Medical Genetics, National Institute of Genetic Engineering and Biotechnology (NIGEB), Tehran, Iran \\ ${ }^{2}$ Department of Pathology, Rasoul Akram Hospital, Iran University of Medical Sciences, Tehran, Iran
}

"Corresponding author: Ghasem Ahangari, Department of Medical Genetics, National Institute of Genetic Engineering and Biotechnology (NIGEB), Tehran, Iran, Tel: +982144580384; Fax: +9821 44580399; E-mail: ghah@nigeb.ac.ir

Rec Date: December 09, 2018, Acc Date: February 11, 2019, Pub Date: February 15, 2019

Copyright: @ 2019 Emruzi Z, et al. This is an open-access article distributed under the terms of the Creative Commons Attribution License, which permits unrestricted use, distribution, and reproduction in any medium, provided the original author and source are credited.

\begin{abstract}
Background and purpose: Many observations showed that hypercholesterolemia can disrupts immune response. Statin drugs that were used for the treatment of hypercholesterolemia patients can interfere in regulation of the immune response and cytokine secretion. The primary aim of the current study was to investigate the immune response among hypercholesterolemia patients, who were treatment-naïve and healthy subjects. The secondary goal of the study was to determine whether atorvastatin can reverse the detrimental effect of hypercholesterolemia on the immune system.
\end{abstract}

Methods: Peripheral blood mononuclear cells (PBMCs) were isolated from 50 patients afflicted with hypercholesterolemia who were treatment-naïve along with 50 sex- and age-matched hypercholesterolemia patients receiving atorvastatin and 50 sex- and age-matched healthy subjects. Quantitative PCR and ELISA methods were used for gene and protein expression analysis of T helper 1 (Th1) and Th2 related cytokines. Additionally, the expression of the cluster of differentiation (CD) markers on T, B, and NK cells were measured by flow cytometry method.

Results: The results showed that hypercholesterolemia and atorvastatin downregulated the expression of Th1related cytokines and elevated the levels of Th2-related cytokines. The expression of cell surface markers, CD25 and CD69, was significantly decreased in the treatment-naïve, and atorvastatin groups.

Conclusion: It seems that atorvastatin is not able to repair the deleterious effects of hypercholesterolemia on the immune system, and elevated levels of cholesterol along with the administration of atorvastatin tilt the Th1/Th2 balance in favor of Th2 and reduce $T$ cell activation.

Keywords: Hypercholesterolemia; Immune response; Atorvastatin; Th1/Th2 balance; $\mathrm{T}$ cell activation.

\section{Introduction}

Hypercholesterolemia is principally defined by high fasting cholesterol that stems from the disturbance in lipid metabolism and genetic defects. It increases the risk of atherosclerosis, cardiovascular diseases, angina, and stroke [1]. Of note, hypercholesterolemia impedes the immune response and cytokine secretion in immune cells. These effects of hypercholesterolemia were due to alteration of cholesterol rates in the cell membrane and cytoplasm of immune cells [2]. Studies indicated that ApoE-/- mice had increased levels of Th2 cells [3] and the decreased number of Th1 cells showing a deficiency in cell-mediated immunity [4-6]. However, the research did not come to a consensus about the association between hypercholesterolemia and the risk of developing cancer $[7,8]$.

Statins, 3-hydroxy-3-methylglutaryl-CoA (HMG-CoA) reductase inhibitors, are a class of compounds used for the treatment of patients with hypercholesterolemia, hyperlipidemia, and cardiovascular diseases [9]. Despite the beneficial effect of atorvastatin on cholesterol lowering, the drug has several side effects including Myalgia [10], rhabdomyolysis, and myopathy [11]. Statins also influence the immune system as they are able to halt $\mathrm{T}$ cell homing, migration, and adhesion, the latter is mediated by the downregulation of integrins, adhesins, and matrix metalloprotease proteins (MMPs) [12,13]. It is thought the modulation of $\mathrm{T}$ cell response is exerted by the hindrance of antigen presenting cells (APCs) development $[14,15]$ through a reduction in major histocompatibility complex II (MHC II) leaving the T cells inactive [16]. As a result, statins predominantly temper the activity of immune cells monocyte/macrophages and $\mathrm{T}$ cells [17]. The ability to avert the activation of Th1 cells upon using statins made them desirable candidates for the alleviation of autoimmune diseases such as rheumatoid arthritis, multiple sclerosis, systemic lupus erythematosus (SLE) [18-20] as well as autoimmune myocarditis [21]. In contrast to animal models, studies performed on human clinical trials showed that atorvastatin did not change any shift in the balance of Th1/Th2 cells [22]. It has been demonstrated that blocking the production of isoprenoids required for prenylation of proteins such as Rho, Rac and Ras superfamily GTPases plays a crucial role in fidelity of statins in amelioration of inflammation $[23,24]$. 
There is a few information about the effect of hypercholesterolemia on the immune system in the literature $[2,6,25]$. All of the researches dealt with the human studies in terms of statin interaction with the $\mathrm{T}$ cell functions were exclusively confined to cultured PBMCs taken from the healthy individuals, patients with autoimmune and cardiovascular diseases [26-28]. Regarding the scarcity of human studies on the role of hypercholesterolemia in $\mathrm{T}$ cell activation and differentiation, we aimed to investigate whether:

- hypercholesterolemia can affect the immune system function;

- atorvastatin can oppress the harmful impact hypercholesterolemia on the immune system.

\section{Methods and Materials}

\section{Study population}

In this study, a total of one-hundred fifty individuals participated that were divided into three groups as the following categorization: 50 patients afflicted with hypercholesterolemia who received no medication for cholesterol lowering (treatment-naïve group), 50 patients who were sex- and age-matched taking atorvastatin at a dose of $10 \mathrm{mg} / \mathrm{kg}$ for at least 4 months (atorvastatin group), and 50 healthy individuals who were sex- and age-matched either (healthy subjects). The participated subjects were chosen from those referring to Hazrate-Rasoul Hospital, Tehran, Iran. The diagnosis of hypercholesterolemia was made in accordance with the measurements of cholesterol at the particular time interval confirming that the patients suffer from persistent hypercholesterolemia (Table 1). The exclusion criteria for the of volunteers were smoking, neurological disorder, cardiovascular diseases, inflammatory and allergen disorders, and diabetes. The protocol used for the sample collection and patient examinations was confirmed by the ethical committee of the National Institute of Genetic Engineering and Biotechnology (NIGEB), and each volunteer was given informed consent. All methods were performed in accordance to Helsinki Declaration.

\begin{tabular}{|l|l|l|l|l|}
\hline Characteristics & Healthy $(\mathbf{n}=\mathbf{5 0})$ & Treatment-naïve $(\mathbf{n}=\mathbf{5 0})$ & Atorvastatin $(\mathbf{n}=\mathbf{5 0})$ & $\mathbf{p}$-value \\
\hline Sex (male/female) & $23 / 27$ & $25 / 25$ & $26 / 24$ & 0.9134 \\
\hline Mean age (range), years & $47(41-55)$ & $49(44-60)$ & $53(49-62)$ & 0.3432 \\
\hline Mean BMI (range), kg/m² & $23.2(20-24)$ & $32.8(29-35)$ & $28.2(26-31)$ & $0.0321^{*}$ \\
\hline Mean cholesterol level \pm SD (mg/dl) & $160.2 \pm 11$ & $300.4 \pm 15$ & $172 \pm 19.8$ & $0.0061^{* *}$ \\
\hline Mean LDL level \pm SD (mg/dl) & $102.2 \pm 11.8$ & $158.8 \pm 14.5$ & $105 \pm 15.6$ & $0.0176^{*}$ \\
\hline Mean HDL level \pm SD (mg/dl) & $40.2 \pm 4.3$ & $42.5 \pm 10.3$ & $39.5 \pm 5.7$ & 0.8971 \\
\hline Mean Triglyceride level \pm SD (mg/dl) & $129.8 \pm 15.8$ & $124.1 \pm 30$ & $122.6 \pm 24.3$ & 0.7692 \\
\hline BMI: Body Mass Index; LDL: Low-Density Lipoprotein; HDL: High-Density Lipoproteins & &
\end{tabular}

Table 1: Demographic and clinical characteristics of samples in this study.

\section{Cell isolation and serum separation}

Whole blood samples $(5 \mathrm{ml})$ were collected from all individuals and poured in $0.5 \mathrm{M}$ EDTA-containing tubes to avoid coagulation. The peripheral blood mononuclear cells (PBMCs) were separated based on the gradient density centrifugation technique by Ficoll hypaque (Pharmacia, Uppsala, Sweden). For the serum separation, blood samples were taken in tubes lacking an anticoagulant, and then they were centrifuged and stored at $-80^{\circ} \mathrm{C}$ for until use.

\section{RNA extraction and cDNA synthesis}

Total RNA was extracted from PBMCs using a High Pure RNA Isolation Kit (Roche, Germany) according to the manufacturer's instructions. The quantity and quality of RNA were determined using NanoDrop 2000 (Wilmington, USA) at $260 \mathrm{~nm}$ and agarose gel analysis. For reverse transcription polymerase chain reaction (RTPCR), 400 ng of total RNA was converted into complementary DNA (cDNA) using Revert Aid First Strand cDNA Synthesis Kit (Thermo Fisher Scientific, Germany) based on manufacturer's protocols. The produced $\mathrm{cDNA}$ was stored at $-20^{\circ} \mathrm{C}$ for spare use.

\section{PCR and Real-Time PCR analysis}

Primers designing were performed by oligo7 software (version 7.56) using the RefSeq sequences of GenBank database as described in Table 2 , the specificity of each primer pair was confirmed by Primer- BLAST online software. A PCR was performed to check for any contaminating DNA and in order to confirm the transcription of interested genes in a final volume of $20 \mu \mathrm{l}$ with master mix PCR (Cinnagen, Tehran, Iran), gene- specific primers $(10 \mathrm{pmol} / \mu \mathrm{l})$, and $\mathrm{cDNA}(1 \mu \mathrm{g})$ in all samples and then loaded them on gel $1.5 \%$.

Real-time-PCR was performed for relative quantification of the mRNA expression of all interested genes in a final volume of $10 \mu \mathrm{l}$, using the SYBR Green Real-time PCR Master Mix (Light Cycler Fast Start DNA Master Plus SYBR Green I, Roche, Germany), and 10 pmol of the previously mentioned primers and $1 \mu \mathrm{g}$ cDNA. The real time PCR protocol was as follows: pre-denaturation at $95^{\circ} \mathrm{C}$ for 600 seconds, denaturation at $95^{\circ} \mathrm{C}$ for 15 seconds, annealing at $60^{\circ} \mathrm{C}$ for 20 seconds, extension at $72^{\circ} \mathrm{C}$ for 20 seconds, with 40 cycles. Identification of fluorescent intensity in each sample was performed by Rotor gene (Termocicler Rotor-Gene 6000 Corbett Research/ Australia). Melting curve analysis showed only one peak for each reaction and this was also confirmed by electrophoresis of PCR products that showed only one band of the expected size. 
Citation: Emruzi Z, Babaheidarian P, Ahangari G (2019) Immune Modulatory Effects of Hypercholesterolemia: Can Atorvastatin Convert the Detrimental Effect of Hypercholesterolemia on the Immune System?. J Mol Biomark Diagn 10: 413. doi:10.4172/2155-9929.1000413

Page 3 of 9

\begin{tabular}{|c|c|c|c|c|}
\hline Genes & $\begin{array}{l}\text { Genbank } \\
\text { Number }\end{array}$ & Forward primer $\left(5^{\prime} \rightarrow 3^{\prime}\right)$ & Reverse primer $\left(5^{\prime} \rightarrow 3^{\prime}\right)$ & Amplicon size (base pair) \\
\hline IL-2 & NM_000586 & ATTACAAGAATCCCAAACTCACCAG & GTTGTTTCAGATCCCTTTAGTTCC & 217 \\
\hline IL-4 & NM_172348 & СтTССССстстGTTCTTССтG & ССTTCTCAGTTGTGTTCTTCTGCTC & 130 \\
\hline IL-5 & NM_000879 & TGCTGATAGCCAATGAGACTCTG & GACTCTCCAGTGTGCCTATTCC & 102 \\
\hline IL-6 & NM_001318095 & TCTGGATTCAATGAGGAGACTTGC & СТСАСТАСТСTСАAАTCTGTTCTGG & 102 \\
\hline IFN-y & NM_000619 & CGGTAACTGACTTGAATGTCCAAC & ACCATTACTGGGATGCTCTTCGAC & 141 \\
\hline TNF- $\alpha$ & NM_000594 & СТССTTCAGACACССTCAACC & CGAAGTGGTGGTCTTGTTGC & 101 \\
\hline T-bet & NM_013351 & CCAAGTTTAATCAGCACCAGACAG & CAAGACCACGTCCACAAACATCC & 131 \\
\hline GATA-3 & NM_001002295 & СССTCATTAAGCCCAAGCGAAG & CAGGGGTCTGTTAATATTGTGAAG & 167 \\
\hline$\beta$-actin & NM_001101 & AGACGCAGGATGGCATGGG & GAGACCTTCAACACCCCAGCC & 161 \\
\hline
\end{tabular}

Table 2: Primers used in Real-Time PCR for cytokine, transcription, and internal control genes.

\section{Cytokine measurements}

The concentration of IFN- $\gamma$, TNF- $\alpha$ and IL- 2 cytokines was assayed in the serum of three studied groups. In this section, a total of 60 individuals were recruited that consisted of 20 subjects ( 11 women +9 men; mean age $=47$ years) in the treatment-naïve group, 20 (10 women, 10 men; average age $=49$ years $)$ patients treated with atorvastatin, and 20 ( 12 women +8 men; mean age $=48$ years $)$ healthy individuals. The aforementioned factors were all analyzed by the commercial kits (R\&D Systems, Minneapolis, Minnesota, USA) according to the manufacturer's instructions. The optical density of the samples was read using an ELISA reader (Spectra Max M2e, Molecular Devices, USA) at $450 \mathrm{~nm}$.

\section{Immunophenotyping}

Cell surface staining was performed for a total of thirty individual consisted of 10 subjects ( 5 women +5 men; mean age $=50$ years) in the treatment-naïve group, 10 (6 women +4 men; mean age $=48$ years $)$ patients in the atorvastatin group, and 10 (5 women +5 men; mean age $=45$ years) healthy subjects. Immunophenotyping was done using antibodies against CD3 (FITC, Dako Denmark), CD4/CD8 (FITC/PE, BD Biosciences), CD25 (PerCP/Cy5.5, Biolegend), CD69 (PerCP/ Cy5.5, Biolegend), CD22 (FITC, Dako, Denmark), CD16 (FITC, Immunostep), CD56 (PE, Immunostep), CD45RO (PE, Dako Denmark). Appropriate isotype controls were used as negative controls to determine the nonspecific staining and background. In the first stage, $100 \mu \mathrm{l}$ of whole blood was poured into the test tube, and the antibodies were added to the recommended dilutions. Then, the tubes were incubated for 30 minutes at $4^{\circ} \mathrm{C}$. After the incubation time, $1 \mathrm{ml}$ of RBC lysis solution was added and incubated for 10-15 minutes at room temperature. In the last step, the sample was run in BD FACS Calibur flow cytometry (BD Biosciences, USA). The obtained data were analyzed by the Flowjo Software (version 7.6.1). Gating was applied to analyze the lymphocytes, and the results were reported as the percentage of CD4- and CD8-positive lymphocytes expressing either CD69 or CD25 surface markers in a total of all T cell population, CD3- and CD22-positive lymphocytes expressing CD45RO marker, and finally, CD16-positive lymphocytes that expressed CD56 surface marker.

\section{Statistical analysis}

For analyzing the real time PCR data, the PCR efficiency (E) and crossing point deviation $(\triangle \mathrm{CP})$ was calculated by LinRegPCR Software (Version 11.0), following the use of Relative Expression Software Tool (REST (c) 2009, Version 2.0.13) for statistical analysis. Normality of other data was determined using the Kolmogorov-Smirnov test. With respect to the data (parametric vs. non-parametric) analysis of variance (ANOVA) and Kruskal-Wallis tests were applied where appropriate followed by post hoc Tukey's test. The data were expressed as the mean \pm standard deviation (SD). The calculation of the comparison was carried out by the SPSS software (version 16; SPSS, Chicago, ILL). The difference between the variables was statistically significant if the $\mathrm{p}$-value was less than 0.05 .

\section{Results}

\section{Hypercholesterolemia and atorvastatin decreased the mRNA expression of Th1-related cytokines}

The results showed that the treatment-naïve and atorvastatin groups had significantly $(\mathrm{p}<0.0001)$ lower the mRNA expression of IL-2, IL-6, IFN- $\gamma$, TNF- $\alpha$ cytokines, and T-bet transcription factor in comparison to the healthy individuals. In addition, the mRNA expression of IFN- $\gamma$, TNF- $\alpha$ cytokines and T-bet was lower in the atorvastatin group compared with the treatment-naive group $(\mathrm{p}<0.01)$; however, the expression of IL-2 and IL-6 remained unchanged (Figure 1).

\section{Hypercholesterolemia and atorvastatin increased the mRNA expression of Th2-related cytokines}

The treatment-naïve group had significantly $(\mathrm{p}<0.05)$ higher levels of cholesterol and LDL, as well as the higher expression of IL-5, and GATA-3 in comparison to the healthy subjects; however, the expression of IL-4 did not significant differ between the two groups. Correspondingly, the treatment with atorvastatin caused a significant upregulation in the mRNA expression of IL-5 and GATA-3. The expression of IL-4 was not affected by the administration of atorvastatin in patients with hypercholesterolemia. On one hand, the expression of GATA-3 was significantly $(\mathrm{p}<0.0001)$ increased $(2$ fold $)$ 
in atorvastatin group when compared with the treatment-naïve group; yet, the expression of Th2-related cytokines namely IL-4 and IL-5 did not significant differ between two groups (Figure 2).

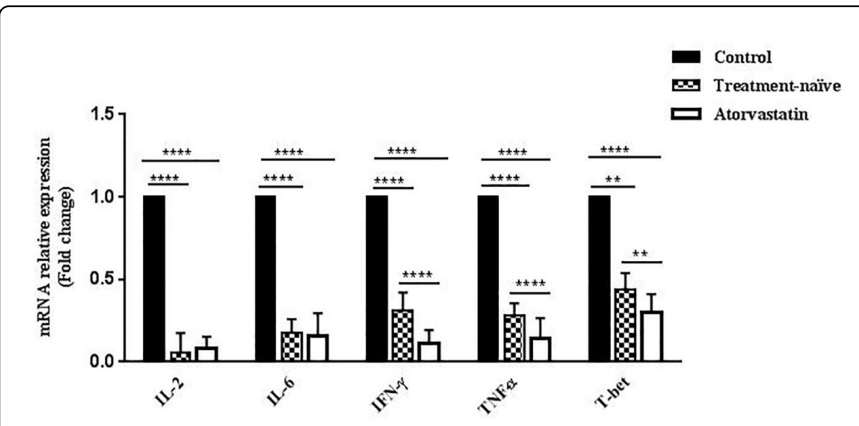

Figure 1: The bar plot indicates the mRNA expression of Th1related genes and T-bet transcription factor in PBMC samples. The expression ratios plotted for IL-2, IL-6, IFN- $\gamma$, TNF- $\alpha$, and T-bet genes were significantly decreased in the treatment-naive and the atorvastatin group patients in comparison to the healthy individuals. The mRNA expression of IFN- $\gamma$, TNF- $\alpha$ cytokines, and T-bet was lower significantly in the atorvastatin group compared with the treatment-naïve group. Error bars represent the standard deviation. Number of subjects in each of groups $=50$. Statistical significance was designated as: ${ }^{* *}, \mathrm{p}<0.01 ;{ }^{* * *}, \mathrm{p}<0.0001$.

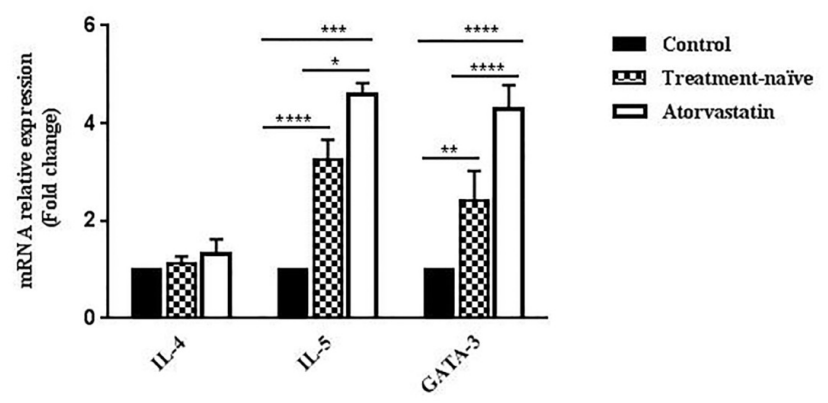

Figure 2: The bar plot indicates the mRNA relative expression patterns of Th2 -related genes and GATA-3 transcription factor in PBMC samples. The treatment-naïve and atorvastatin groups had significantly higher the mRNA expression of IL-5 and GATA-3 genes in comparison to the healthy individuals. The mRNA expression of GATA-3 was increased about 2 folds in atorvastatin group when compared with the treatment-naïve group significantly. Error bars represent standard deviation. Number of subjects in each of groups $=50$. Statistical significance was designated as: ${ }^{*}, p<0.05$; ${ }^{* *}, \mathrm{p}<0.01 ;{ }^{* * *}, \mathrm{p}<0.001 ;{ }^{* * *}, \mathrm{p}<0.0001$.

\section{Effect of hypercholesterolemia and atorvastatin on protein levels of Th1- and Th2-related cytokines}

The results showed that hypercholesterolemia leads to a significant decrease $(p<0.0001)$ in the expression of Th1 related cytokines including IL-2, IFN- $\gamma$, and TNF- $\alpha$ in the treatment-naïve group in comparison to the healthy subjects. In line with this, it was shown that atorvastatin significantly $(\mathrm{p}<0.0001)$ decreased the gene expression of
IL-2, IFN- $\gamma$, and TNF- $\alpha$ in those patients underwent statin therapy in comparison to the healthy individuals. Individuals treated with atorvastatin had significantly $(p<0.01)$ lower levels of TNF- $\alpha$ than those who were treatment-naïve. On one hand, hypercholesterolemia did not significant effect in the expression of Th2 related cytokines in the treatment-naïve group in comparison to the healthy subjects. Correspondingly, the treatment with atorvastatin caused a significant increase in the expression of IL-5 in comparison to the healthy subjects while the expression of IL- 4 was not affected by the administration of atorvastatin in patients with hypercholesterolemia (Figure 3).

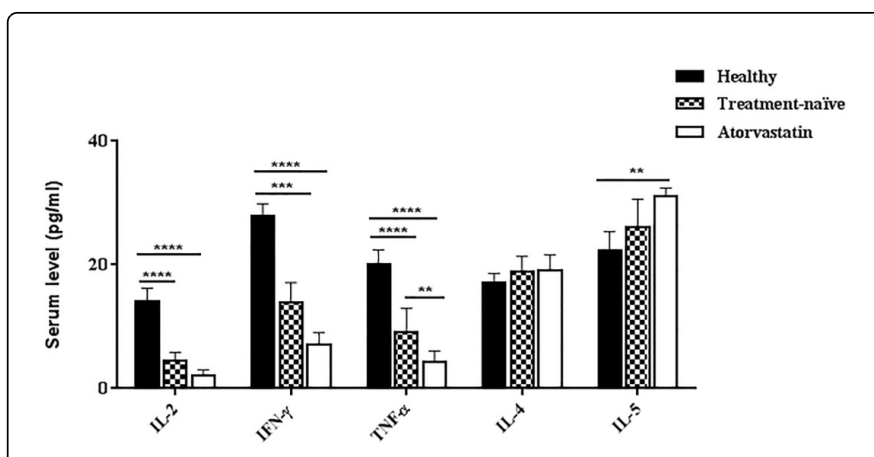

Figure 3: The bar plot shows the serum level of IL-2, IFN- $\gamma$, TNF- $\alpha$, IL-4 and IL-5 in all groups. The expression ratios plotted for Th1realated proteins were found to be significantly decreased in treatment-naïve and atorvastatin group patients in comparison to healthy subject. The level of TNF- $\alpha$ was lower in atorvastatin group compared to the treatment-naive group. The expression ratios plotted for Th2-realated proteins did not differ between three groups except IL-5 were found to be significantly increased in atorvastatin group patients in comparison to healthy subject. Error bars represent standard deviation. Number of subjects in each of groups $=20$. Statistical significance was designated as: ${ }^{* *}, \mathrm{p}<0.01{ }^{* * *}$, $\mathrm{p}<0.001{ }^{* * * *}, \mathrm{p}<0.0001$.

\section{Correlations of Th1- and Th2-related cytokines protein expression with patient's characteristics}

Table 3 shows that no significant correlation between the age, and the expression of all the IL-2, IFN- $\gamma$, TNF- $\alpha$, IL- 4 and IL- 5 cytokines. A significant negative correlation was found between the level of IL-2 and the BMI of all individuals $(\mathrm{r}=-0.684 ; \mathrm{p}<0.05)$. The data also indicated that LDL concentration was significantly negative correlated with the expression of IL-2, IFN- $\gamma$, and TNF- $\alpha(r=-0.73, r=-0.878$, and $\mathrm{r}=-0.927 ; \mathrm{p}<0.05$, respectively), while there are no significant correlation with the expression of IL-4 and IL-5. Accordingly, while there are significant correlations between the levels of IL-2, TNF- $\alpha$ and IL-5 with cholesterol level $(r=-0.896, r=-0.724, r=+0.649 ; \mathrm{p}<0.05$, respectively), no significant correlation was found between the cholesterol levels and the expression of IFN- $\gamma$ and IL-4.

\section{Hypercholesterolemia and atorvastatin decreased expression of $\mathrm{T}$ cell activation markers}

Flow cytometry analysis of the surface receptors of the $\mathrm{T}$ cells showed that the treatment-naïve group had a significant lower $(\mathrm{p}<0.05)$ number of CD4+ CD25+, CD4+ CD69+, CD8+ CD25+ , and CD8+ CD69+ cells over that of the healthy subjects. Similar results were obtained in patients received atorvastatin in comparison to the 
Citation: Emruzi Z, Babaheidarian P, Ahangari G (2019) Immune Modulatory Effects of Hypercholesterolemia: Can Atorvastatin Convert the Detrimental Effect of Hypercholesterolemia on the Immune System?. J Mol Biomark Diagn 10: 413. doi:10.4172/2155-9929.1000413

Page 5 of 9

healthy individuals except for the number of CD4+ CD25+ cells that were not significantly affected in response to atorvastatin treatment. The number of all $\mathrm{T}$ cell groups did not significantly differ between the treatment-naïve and atorvastatin groups (Figure 4).

\begin{tabular}{|c|c|c|c|c|}
\hline \multirow[b]{2}{*}{ Proteins } & $\begin{array}{l}\text { Age (years } \\
\text { old) }\end{array}$ & BMI $\left(\mathrm{kg} / \mathrm{m}^{2}\right)$ & $\begin{array}{l}\text { Cholesterol } \\
\text { (mg/dl) }\end{array}$ & LDL (mg/dl) \\
\hline & $<49 \geq 49$ & $<32.8 \geq 32.8$ & $<248 \geq 248$ & $<148 \geq 148$ \\
\hline \multirow[b]{2}{*}{ IL-2 } & $r=+0.175$ & $r=-0.684$ & $r=-0.896$ & $r=-0.732$ \\
\hline & $p=0.287$ & $p=0.01^{*}$ & $\mathrm{p}=0.0007^{\star \star \star}$ & $p=0.030^{*}$ \\
\hline \multirow[b]{2}{*}{ IFN-y } & $r=+0.214$ & $r=-0.196$ & $r=-0.215$ & $r=-0.878$ \\
\hline & $p=0.886$ & $p=0.392$ & $p=0.171$ & $p=0.029^{*}$ \\
\hline \multirow[b]{2}{*}{ TNF- $\alpha$} & $r=+0.118$ & $r=-0.216$ & $r=-0.724$ & $r=-0.927$ \\
\hline & $p=0.728$ & $p=0.534$ & $p=0.043^{*}$ & $p=0.004^{* *}$ \\
\hline \multirow[b]{2}{*}{ IL-4 } & $r=+0.253$ & $r=+0.186$ & $r=+0.189$ & $r=+0.254$ \\
\hline & $p=0.457$ & $p=0.856$ & $p=0.256$ & $p=0.321$ \\
\hline \multirow[b]{2}{*}{ IL-5 } & $r=+0.196$ & $r=+0.227$ & $r=+0.649$ & $r=+0.298$ \\
\hline & $p=0.792$ & $p=0.537$ & $\mathrm{p}=0.041^{*}$ & $p=0.085$ \\
\hline \multicolumn{5}{|c|}{$\begin{array}{l}\text { BMI: Body Mass Index; LDL: Low Density Lipoprotein; }{ }^{*}, p<0.05 ;{ }^{* *}, p<0.01 ; * * * \\
\text { * }<0.001\end{array}$} \\
\hline
\end{tabular}

Table 3: Association of Th1- and Th2- related cytokines with patient's characteristics in the treatment-naïve group.

\section{Effect of hypercholesterolemia and atorvastatin on the phenotype of T, B memory, and NK cells as well as the CD4/CD8 ratio}

It was shown that $1.9 \%$ of $\mathrm{B}$ cells in the treatment-naive group were positive for CD22 and CD45RO that was significantly $(\mathrm{p}<0.0001)$ lower than the number of $\mathrm{CD} 22+\mathrm{CD} 45 \mathrm{RO}+$ cells in the healthy subjects. However, the number of CD3+ T cells and CD56+ CD16+ NK cells remained unchanged. The results also revealed that the treatment with atorvastatin caused a significant $(\mathrm{p}<0.001)$ diminish in the number of cells positive for CD22 and CD45RO compared with the healthy individuals; yet, the number of CD3+ T cells and CD56+ CD16+ NK cells did not significantly differ between the two groups. The ratio of CD4 to CD8 in the treatment-naïve patients and patients received atorvastatin was $3.23 \%$ and $3.27 \%$, respectively that shows both hypercholesterolemia and receiving atorvastatin can lead to the decrease $(\mathrm{p}<0.05)$ in the ratio of those $\mathrm{CD}$ markers in comparison to the healthy individuals. The phenotype of T, B memory, and NK cells as well as the CD4/CD8 ratio did not significantly differ between the treatment-naïve and atorvastatin groups (Figure 5).

The comparison between the number of CD69+ and CD25+ T cells showed that the number of CD69+ T cells was significantly elevated in the healthy group compared with the other groups. Besides, when the number of CD4+ CD25+, CD8+ CD25+, CD4+ CD69+, and CD8+ CD69+ was analyzed in all groups, the percentage of cells expressing CD8 and CD25 was more affected in the treatment-naïve and atorvastatin group compared with the healthy control in which a significant decrease in the number of those cells was reported in the treatment-naïve and the atorvastatin groups in comparison to the healthy subjects (Figure 6).

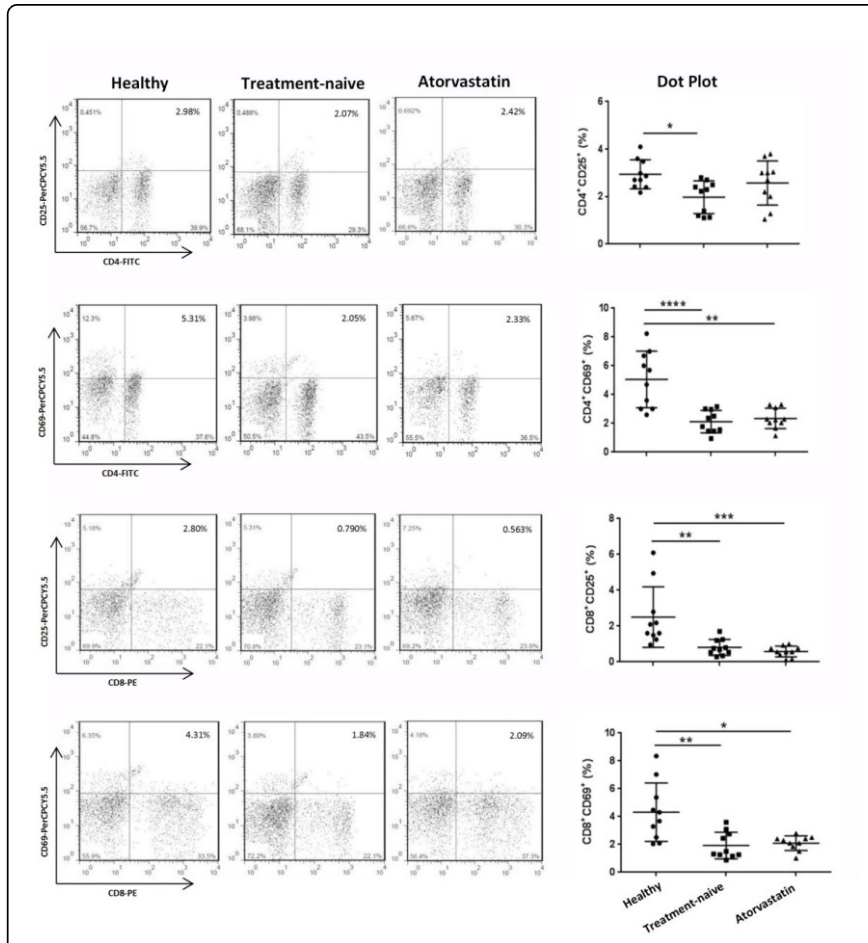

Figure 4: The effect of hypercholesterolemia and atorvastatin on the expression of $\mathrm{T}$ cell activation markers. The expression level of the cell surface activation markers on $\mathrm{T}$ cells was shown in all groups. The number of each $\mathrm{T}$ cell surface markers has been determined by flow cytometry analysis. The results of flow cytometry analysis were simplified and expressed as dot plots. Post hoc Tukey's test; $\mathrm{n}=10$. Statistical significance was designated as: ${ }^{*}, \mathrm{p}<0.05 ;{ }^{* *}, \mathrm{p}<0.01 ;{ }^{* * *}$, $\mathrm{p}<0.001{ }^{* * * *}, \mathrm{p}<0.0001$.

\section{Correlation of the $\mathrm{CD}$ markers expression with patient characteristics}

In Table 4, there was no correlation between the age and BMI of individuals and the expressions of all CD markers. There was a significant negative correlation between the cholesterol levels and the number of CD4+ CD25+, CD8+ CD25+, and CD8+ CD69+ cells ( $\mathrm{r}=$ $-0.956, r=-0.726$ and $r=-0.914 ; p<0.05$, respectively). Notably, the ratio of CD4 to CD8 was significantly linked to the concentrations of cholesterol in patients who were treatment-naïve. Furthermore, it was shown that the levels of LDL were negatively correlated with the number of CD4 cells positive for CD25 and CD69 $(r=-0.868$ and $r=$ $-0.674 ; \mathrm{p}<0.05$, respectively).

\section{Discussion}

Hypercholesterolemia is one of the major problems of the developed countries caused by the interaction of the environmental factors and genetic predisposition [29]. Statins are a potent class of chemical compounds that have been shown to inhibit the synthesis of cholesterol and thereby lower the levels of circulating free cholesterol in the blood [30]. Many efforts have been made to illuminate the interaction of hypercholesterolemia and statins on the immune system function. However, those studies were exclusively confined to in vitro 
research performed on the cultured PBMCs from healthy individuals and patients who were afflicted with autoimmune and cardiovascular diseases $[6,31,32]$. To get a better insight on the anti-inflammatory effect of hypercholesterolemia and statins on the functionality of the immune system, we investigated the effect of hypercholesterolemia and atorvastatin on $\mathrm{T}$ cell differentiation, Th1/Th2 polarization, and $\mathrm{T}$ cell activation in patients who were considered either treatment-naïve or atorvastatin users. We also aim to specify whether atorvastatin could avert the Th2-biased humoral immunity in patients with hypercholesterolemia by lowering cholesterol level in these patients.

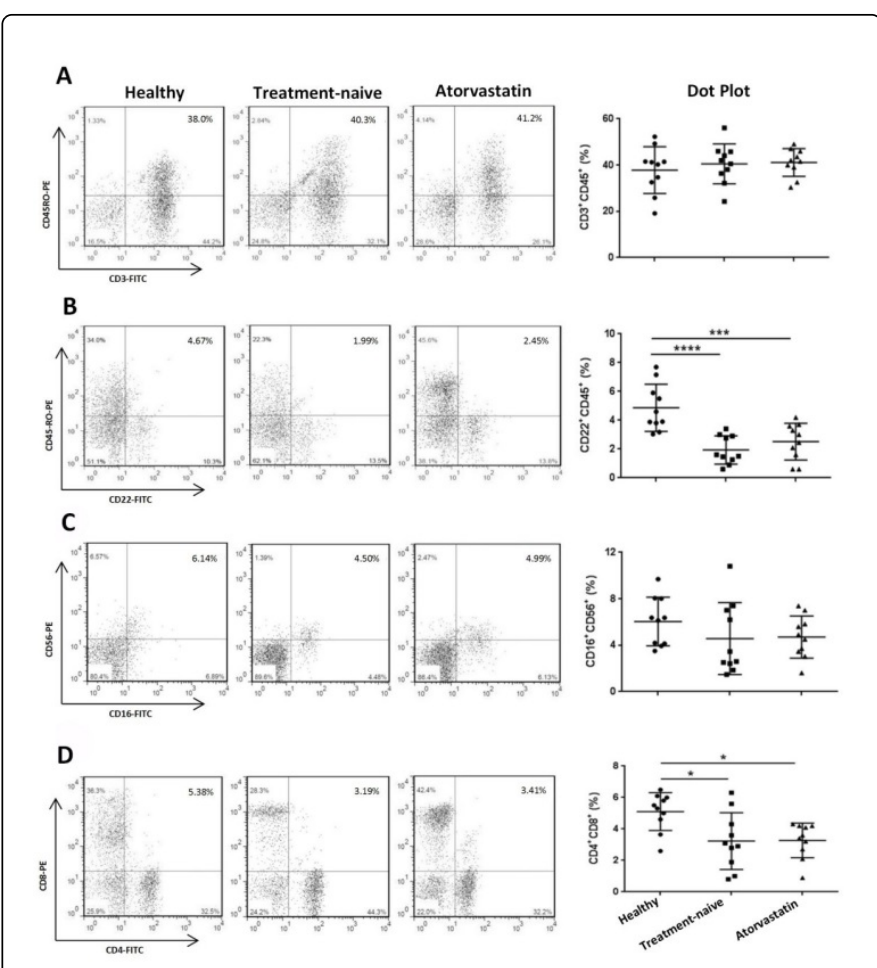

Figure 5: The effect of hypercholesterolemia and atorvastatin on the expression of cell surface marker of T, B memory cells, and NK cells, as well as the CD4/CD8 ratio. Hypercholesterolemia and atorvastatin decreased the percentage of CD22+ CD45RO+ cells (B) and the CD4/CD8 ratio (D) but had no effect on T memory and CD56CD16 NK cells (A, C). The number of each cell types was analyzed by flow cytometry analysis, and the results were simplified and depicted as dot plots. Post hoc Tukey' test; $\mathrm{n}=10$. Statistical significance was designated as: ${ }^{*}, \mathrm{p}<0.05 ;{ }^{* * *}, \mathrm{p}<0.001$.

In this study, we observed that hypercholesterolemia and atorvastatin shifted the ratio of Th1/Th2 in favour of Th2 resulted in mitigation of the cell-mediated immunity and $\mathrm{T}$ cell activity. On one hand, it was shown that hypercholesterolemia and atorvastatin incited the humoral immunity system. Hence, atorvastatin could not reverse the harmful effects of hypercholesterolemia on the immune system. Where the atorvastatin is a more safety and well-tolerability amongst statins family, we chose it for the present experiment [33].

Reports indicated mice lacking apolipoprotein $\mathrm{E}$ (hypercholesterolemia model) had an impaired immune system $[25,34,35]$. It was also demonstrated that a high cholesterol diet obstructs the lymphocyte proliferation and T cell activity [36]. Zhou et al. suggested that hypercholesterolemia drives Th1/Th2 balance towards Th2-related cytokine release [4,6]. Consistent with our results, Lei et al. showed that elevated levels of cholesterol and LDL in hyperlipidemia patients resulted in a decrease in Th1-related cytokines such as IFN- $\gamma$, TNF- $\alpha$, IL-2, IL- 6 , and T-bet transcription factor. Inversely, hypercholesterolemia leads to increasing the expression of Th2-related cytokine such as IL-5 and GATA-3 transcription factor. It is of note that T-bet and GATA-3 are crucial transcription factors in differentiation of Th 0 cells into the development of Th 1 and Th 2 cells, respectively [33,37]. Studies have indicated that high levels of cholesterol in the cell membrane can make a disturbance in the localization of the raft-associated signaling molecule Lck [38] and it increases Th1 differentiation of CD4+ $\mathrm{T}$ cells [39]. The increased amount of cholesterol is able to halt the differentiation of CD8 T cells into the Tc9 cells and subsequently, preventing the anti-tumor activity of CD8+ T cells [40].

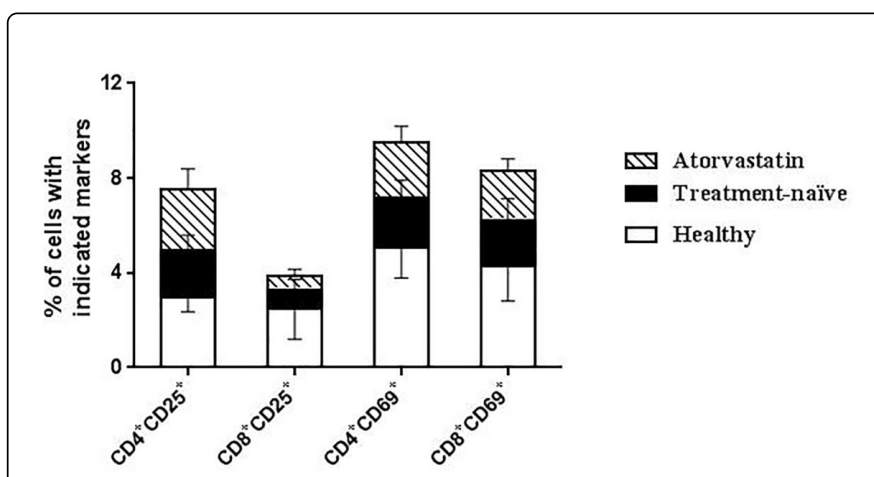

Figure 6: The stacked bars show the cell percentage for various CD markers in studied groups. Means $\pm \mathrm{SD}$; post hoc Tukey's test; $\mathrm{n}=10$.

In parallel, in vitro studies have displayed that statin drugs, which used for treatment of hypercholesterolemia patients, impair the proper function of the immune cells and consequently weaken their timely response to infectious agents [41]. The inhibitory effects of statins on Th1 cells caused simvastatin is used for the treatment of various inflammatory diseases such as arthritis in rodent models [26]. In contrast to animal experiments [33], oral administration of simvastatin had no significant effect on $\mathrm{T}$ helper polarization [28]. According to our results, it is suggested that atorvastatin decrease the mRNA expression of IFN- $\gamma$, TNF- $\alpha$, IL- 2 and IL- 6 and T-bet transcription factor. In addition, it increases the expression of Th2- related cytokine expressions namely IL-5 and GATA3 transcription factor in patients with hypercholesterolemia. One of the possible underlying mechanism in which atorvastatin can drive the Th1/Th2 balance in favour of the overproduction of Th2 is the induction of STAT6 phosphorylation and up-regulation of GATA-3 transcription factor [42]. It can accordingly inhibit the differentiation of Th1 cells via the preventing STAT4 phosphorylation and down-regulation of T-bet transcription factor [43]. In this context, atorvastatin can downregulate expression of IFN$\gamma$ through disruption of MHC II transcription activation and finally, resulting in the inhibition of antigen presentation on APCs and damping the generation of proinflammatory Th1 cells [44]. We measured the protein levels of Th1- and Th2-related cytokines by the ELISA method in which hypercholesterolemia and atorvastatin both lowered the concentrations of Th1-related cytokines such as IL-2, IFN$\gamma$, and TNF- $\alpha$ in serum and concentrations of IL-5 as Th2-related cytokine increased by atorvastatin. The obtained data from the protein 
Citation: Emruzi Z, Babaheidarian P, Ahangari G (2019) Immune Modulatory Effects of Hypercholesterolemia: Can Atorvastatin Convert the Detrimental Effect of Hypercholesterolemia on the Immune System?. J Mol Biomark Diagn 10: 413. doi:10.4172/2155-9929.1000413

Page 7 of 9

levels corroborated the mRNA expressions of their cognate genes. It should be noted that the correlation of Th1- and Th2-related cytokines was calculated with the demographic characteristics of patients who were treatment-naïve in which the expression of IL-2, TNF- $\alpha$ and IL-5 was associated with the concentration of cholesterol in the serum of hypercholesterolemia patients. In a suitable manner, the level of LDL was also attributed to the levels of IL-2, IFN- $\gamma$ and TNF- $\alpha$ in the above patients.

\begin{tabular}{|c|c|c|c|c|}
\hline \multirow[b]{2}{*}{ CD markers } & Age (years old) & BMI $\left(\mathbf{k g} / \mathbf{m}^{2}\right)$ & Cholesterol (mg/dl) & LDL (mg/dl) \\
\hline & $<49 \geq 49$ & $<32.8 \geq 32.8$ & $<248 \geq 248$ & $<148 \geq 148$ \\
\hline \multirow[b]{2}{*}{ CD4CD25 } & $r=+0.184$ & $r=-0.134$ & $r=-0.956$ & $r=-0.868$ \\
\hline & $p=0.784$ & $p=0.763$ & $p=0.002^{* *}$ & $p=0.009^{* *}$ \\
\hline \multirow[b]{2}{*}{ CD4CD69 } & $r=+0.213$ & $r=-0.214$ & $r=-0.216$ & $r=-0.674$ \\
\hline & $p=0.897$ & $p=0.975$ & $p=0.347$ & $p=0.023^{*}$ \\
\hline \multirow[b]{2}{*}{ CD8CD25 } & $r=+0.182$ & $r=-0.189$ & $r=-0.726$ & $r=-0.274$ \\
\hline & $p=0.533$ & $p=0.543$ & $p=0.044^{*}$ & $p=0.265$ \\
\hline \multirow[b]{2}{*}{ CD8CD69 } & $r=+0.138$ & $r=-0.243$ & $r=-0.914$ & $r=-0.194$ \\
\hline & $p=0.461$ & $p=0.586$ & $p=0.003^{* \star}$ & $p=0.758$ \\
\hline \multirow[b]{2}{*}{ CD3CD45 } & $r=+0.245$ & $r=-0.194$ & $r=-0.214$ & $r=-0.169$ \\
\hline & $p=0.364$ & $p=0.456$ & $p=0.677$ & $p=0.885$ \\
\hline \multirow[b]{2}{*}{ CD3CD22 } & $r=+0.264$ & $r=-0.149$ & $r=-0.271$ & $r=-0.253$ \\
\hline & $p=0.802$ & $p=0.939$ & $p=0.969$ & $p=0.353$ \\
\hline \multirow[b]{2}{*}{ CD16CD56 } & $r=+0153$ & $r=-0.215$ & $r=-0.213$ & $r=-0.299$ \\
\hline & $p=0.602$ & $p=0.935$ & $p=0.478$ & $p=0.863$ \\
\hline \multirow[b]{2}{*}{ CD4CD8 } & $r=+0.231$ & $r=-0.167$ & $r=-0.698$ & $r=-0.267$ \\
\hline & $p=0.593$ & $p=0.300$ & $p=0.041^{*}$ & $p=0.901$ \\
\hline
\end{tabular}

Table 4: Correlations of CD markers expression in untreated hypercholesterolemia patients with patient characteristics.

Leung et al. and Weber et al. found that atorvastatin can boost the expression of Th2 cells $[26,45]$. Link et al. showed that rosuvastatin resulted in a rapid reduction in plasma cytokines such as IFN- $\gamma$, IL-6, and TNF- $\alpha$ [46]. Similar to our results, Shimada et al. showed that atorvastatin shifted the balance of Th1/Th2 in favor of Th2 in patients with the acute coronary syndrome (ACS) [27]. Prevention of protein prenylation is one of the bona fide strategies that atorvastatin employs to dampen the signal transduction of pathways involved in inflammation $[33,47,48]$. IL-2 is required for the initiation and activation of T-cell-mediated immunity playing an important role in combating the cancer cells [49]. Along with IL-2, interferon gamma (IFN- $\gamma$ ) is able to eliminate tumor tissue by means of elevating Th1 cells and $\mathrm{T}$ cell activation [50,51]. IFN $-\gamma$ give rises to the upregulation of MHC II in APCs driving T cell to secret cytolytic compounds to kill the tumor cells [52]. TNF- $\alpha$ has been shown a potent tumor killer agent exerting anti-cancer activity both in vivo and in vitro [53]. The TNF- $\alpha$ is involved in the extrinsic pathway of apoptosis and necrosis in damaged and tumor cells [54]. The IL-6 as the Th1-associated cytokines play a key role in cell-mediated immunity thereby stimulation, proliferation, and differentiation of cytotoxic $\mathrm{T}$ cells in the presence of IL-2 $[55,56]$. IL-5 is also an important interleukin which is under the control of GATA-3 transcription factor playing a pivotal role in the pathogenesis of asthma hyper-eosinophilic syndromes, and eosinophil-dependent inflammatory diseases [57]. Collectively, in the present study, hypercholesterolemia and atorvastatin through down regulation of cytokines with anti-tumor effects might impair cell mediated immunity and probably increase the risk of cancer. Also, these by upregulation of IL-5 cytokine and GATA-3 transcription factor might induce humoral immunity and increase the risk of allergic dependent diseases.

The previous studies showed that increased levels of cholesterol abolish the $\mathrm{T}$ cell homeostasis leading to impaired the $\mathrm{T}$ cell function $[58,59]$. A high cholesterol diet can affect the expression and differentiation of $\mathrm{T}$ regulatory cells (Treg) [60]. In the present study, it was observed that high level of cholesterol and LDL decreased the expression of CD69 and CD25 activation markers on CD4 and CD8 T cells and reduced memory $\mathrm{B}$ cells but had no effect on T memory cells. Furthermore, the correlation analysis revealed that the number of CD4+ CD25+ and CD8+ CD69+ cells is directly associated with the levels of cholesterol and a less extent with the LDL concentration in sera of hypercholesterolemia patients. The ratio of CD4 to CD8 was correlated with the levels of cholesterol as well. It is alleged that cholesterol is needed for stabilization of the cell membrane, especially in lipid raft domain which binds to the chain of TCR and facilitates 
dimerization of TCR giving rise to an increase in the affinity of T cell receptors to their cognate antigens [61]. Guo et al. observed that cholesterol can modify receptor signaling through the elevation of different conformational states in membrane receptors and change the composition of $\mathrm{T}$ cell membrane resulting to the altered $\mathrm{T}$ cell operation [62].

There are contradictory reports about the impact of statins on the expression of CD25 and CD69 on the T cell surface. A study by Blank et al. they disclosed that atorvastatin lowered the expression of CD25 and CD69 on the T cells [63], whereas Guo et al. demonstrated that Fluvastatin inhibited CD69 expression in vitro, but it did not affect the expression of CD25 [64]. In this study, we detected decreased expression of CD8+ CD69+, CD8+ CD25+, CD4+ CD69+ cells in response to atorvastatin treatment while the expression of CD4+ $\mathrm{CD} 25+$ did not alter. Interestingly, despite a decrease in the number of memory $\mathrm{B}$ cells in response to administration of atorvastatin, the number of memory $\mathrm{T}$ cells remained unchanged. We also exhibited the decreased number of CD8+ CD25+ cells in the treatment-naive and the atorvastatin groups compared to the healthy controls.

The preventing effect of atorvastatin on the $\mathrm{T}$ cell activation is mediated by the disruption of APCs maturation [42]. Additionally, atorvastatin is capable of interfering with the TCR signaling pathways via dysregulation of small Ras-like GTPases and the Rab-dependent pathways that are involved in receptor endocytosis [42]. It also blocks LFA-1-ICAM-1 interaction by binding to LFA-1 [16]. In agreement on our results, Kanda et al. reported that low-dose simvastatin decreased the ratio of $\mathrm{CD} 4$ to $\mathrm{CD} 8 \mathrm{~T}$ cells when administered in patients with rheumatoid arthritis [65]. We observed a significant decrease in the ratio of CD4/CD8 in peripheral blood of the atorvastatin group. Also, high level of cholesterol and LDL obtained similar results about $\mathrm{CD} 4 / \mathrm{CD} 8$ ratios in the treatment-naïve group. The low ratio of CD4 to CD8 can raise the risk of cancer because of lacking a sufficient number of Th1 cells [66].

\section{Conclusion}

Altogether, regarding our study, it seems that hypercholesterolemia can disrupt immune system through effect of $\mathrm{T}$ cell activation and differentiation. On the other hand, besides of beneficial effect of atorvastatin on cholesterol lowering, it diminished the activation of $\mathrm{T}$ cells, made a perturbation in inflammatory cytokines, and is not able to repair the deleterious effects of hypercholesterolemia on the immune system.

\section{Acknowledgements}

This project was supported by Center for International Scientific Studies and Collaboration (CISSC) [grant number, 715] and National Institute for Genetic Engineering and Biotechnology (NIGEB). We also thank Professor Hannes Stockinger, Medical University of Vienna, Austria for his generous support and participant individuals for study population.

\section{References}

1. Shattat GF (2015) A review article on hyperlipidemia: types, treatments and new drug targets. Biomed Pharmacol J 7: 399-409.

2. Lei L, Li H, Yan F, Xiao Y (2013) Hyperlipidemia impaired innate immune response to periodontal pathogen porphyromonas gingivalis in apolipoprotein E knockout mice. PLoS One 8: e71849.
3. Dansky HM, Charlton SA, Harper MM, Smith JD (1997) T and B lymphocytes play a minor role in atherosclerotic plaque formation in the apolipoprotein E-deficient mouse. Proc Natl Acad Sci 94: 4642-4646.

4. Zhou X, Paulsson G, Stemme S, Hansson GK (1998) Hypercholesterolemia is associated with a T helper (Th) $1 /$ Th2 switch of the autoimmune response in atherosclerotic apo E-knockout mice. J Clin Inves 101: 1717-1725.

5. Robertson AK, Zhou X, Strandvik B, Hansson GK (2004) Severe hypercholesterolaemia leads to strong Th2 responses to an exogenous antigen. Scand J Immunol 59: 285-293.

6. Zhou X, Johnston TP, Johansson D, Parini P, Funa K, et al. (2009) Hypercholesterolemia leads to elevated TGF- $\beta 1$ activity and T helper 3dependent autoimmune responses in atherosclerotic mice. Atherosclerosis 204: 381-387.

7. Font-Burgada J, Sun B, Karin M (2016) Obesity and cancer: the oil that feeds the flame. Cell Metab 23: 48-62.

8. Tie G, Yan J, Khair L, Messina JA, Deng A, et al. (2017) Hypercholesterolemia increases colorectal cancer incidence by reducing production of NKT and $\gamma \delta$ T cells from hematopoietic stem cells. Cancer Res 77: 2351-2362.

9. Silverstein DM (2003) Indications and outcome of treatment of hyperlipidemia in pediatric allograft recipients. Pediatr Tranplant 7: 7-10.

10. Khan A, Maki KC, Ito MK, Cohen JD, Sponseller CA, et al. (2015) Statin associated muscle symptoms: characteristics of patients and recommendations by providers. J Clin Lipidol 9: 460.

11. Tomaszewski M, Stępień KM, Tomaszewska J, Czuczwar SJ (2011) Statininduced myopathies. Pharmacol Rep 63: 859-866.

12. Weitz-Schmidt G (2002) Statins as anti-inflammatory agents. Trends Pharmacol Sci 23: 482-487.

13. Blanco-Colio LM, Tuñón J, Martín-Ventura JL, Egido J (2003) Antiinflammatory and immunomodulatory effects of statins. Kidney Int 63: $12-23$.

14. Yilmaz A, Reiss C, Weng A, Cicha I, Stumpf C, et al. (2006) Differential effects of statins on relevant functions of human monocytederived dendritic cells. J Leukoc Biol 79: 529-538.

15. Hillyard DZ, Cameron AJ, McDonald KJ, Thomson J, MacIntyre A, et al. (2004) Simvastatin inhibits lymphocyte function in normal subjects and patients with cardiovascular disease. Atherosclerosis 175: 305-313.

16. Weitz-Schmidt G, Welzenbach K, Brinkmann V, Kamata T, Kallen J, et al. (2001) Statins selectively inhibit leukocyte function antigen-1 by binding to a novel regulatory integrin site. Nat Med 7: 687.

17. Cheng X, Ding Y, Xia C, Tang T, Yu X, et al. (2009) Atorvastatin modulates $\mathrm{Th} 1 / \mathrm{Th} 2$ response in patients with chronic heart failure. J Card Fail 15: 158-162.

18. McCarey DW, McInnes IB, Madhok R, Hampson R, Scherbakova O, et al. (2004) Trial of Atorvastatin in Rheumatoid Arthritis (TARA): doubleblind, randomised placebo-controlled trial. Lancet 363: 2015-2021.

19. Noel B (2007) Lupus erythematosus and other autoimmune diseases related to statin therapy: a systematic review. Journal of the European Academy of Dermatology and Venereology 21: 17-24.

20. Mowla K, Rajai E, Ghorbani A, Dargahi-Malamir M, Bahadoram M, et al. (2016) Effect of atorvastatin on the disease activity and severity of rheumatoid arthritis: double-blind randomized controlled trial. J Clin Diagn Res 10: OC32.

21. Liu W, Li WM, Gao C, Sun NL (2005) Effects of atorvastatin on the Th1/Th2 polarization of ongoing experimental autoimmune myocarditis in Lewis rats. J Autoimmun 25: 258-263.

22. Coward W, Chow SC (2006) Effect of atorvastatin on TH1 and TH2 cytokine secreting cells during $\mathrm{T}$ cell activation and differentiation. Atherosclerosis 186: 302-309.

23. Rando RR (1996) Chemical biology of protein isoprenylation/ methylation. Biochimica et Biophysica Acta 1300: 5-16.

24. Hernandez-Perera O, Pérez-Sala D, Soria E, Lamas S (2000) Involvement of Rho GTPases in the transcriptional inhibition of preproendothelin-1 
gene expression by simvastatin in vascular endothelial cells. Circ Res 87 616-622.

25. Vonk AG, De Bont N, Netea MG, Demacker PN, Van Der Meer JW, et al. (2004) Apolipoprotein-E-deficient mice exhibit an increased susceptibility to disseminated candidiasis. Sabouraudia 42: 341-348.

26. Leung BP, Sattar N, Crilly A, Prach M, McCarey DW, et al. (2003) A novel anti-inflammatory role for simvastatin in inflammatory arthritis. J Immunol 170: 1524-1530.

27. Shimada K, Miyauchi K, Daida H (2004) Early intervention with atorvastatin modulates $\mathrm{TH} 1 / \mathrm{TH} 2$ imbalance in patients with acute coronary syndrome: from bedside to bench. Circulation 109: e213-e214.

28. Vollmer T, Key L, Durkalski V, Tyor W, Corboy J, et al. (2004) Oral simvastatin treatment in relapsing-remitting multiple sclerosis. Lancet 363: 1607-1608.

29. Jain KS, Kathiravan MK, Somani RS, Shishoo CJ (2007) The biology and chemistry of hyperlipidemia. Bioorg Med Chem 15: 4674-4699.

30. World Health Organization (2002) The world health report: reducing risks, promoting healthy life.

31. Rezaie-Majd A, Maca T, Bucek RA, Valent P, Müller MR, et al. (2002) Simvastatin reduces expression of cytokines interleukin-6, interleukin-8, and monocyte chemoattractant protein-1 in circulating monocytes from hypercholesterolemic patients. Arterioscler Thromb Vasc Biol 22: 1194-1199.

32. Földes G, Anker SD, von Haehling S (2009) Atorvastatin modulates Th1/Th2 response in patients with chronic heart failure. J Card Fail 15: 551.

33. Youssef S, Stüve O, Patarroyo JC, Ruiz PJ, Radosevich JL, et al. (2002) The HMG-CoA reductase inhibitor, atorvastatin, promotes a Th2 bias and reverses paralysis in central nervous system autoimmune disease. Nature 420: 78-84.

34. Bont D, Der Meer V (2000) Apolipoprotein Edeficient mice have an impaired immune response to Klebsiella pneumoniae. Eur J Clin Invest 30: $818-822$.

35. Ludewig B, Jäggi $M$, Dumrese $T$, Brduscha-Riem $K$, Odermatt $B$, et al. (2001) Hypercholesterolemia exacerbates virus-induced immunopathologic liver disease via suppression of antiviral cytotoxic $\mathrm{T}$ cell responses. J Immunol 166: 3369-3376.

36. Lee Y, Kim J, An J, Lee S, Lee H, et al. (2017) Restoration of Declined Immune Responses and Hyperlipidemia by Rubus occidenalis in DietInduced Obese Mice. Biomol Ther 25: 140.

37. Yamashita M, Ukai-Tadenuma M, Miyamoto T, Sugaya K, Hosokawa H, et al. (2004) Essential role of GATA3 for the maintenance of type 2 helper $\mathrm{T}$ (Th2) cytokine production and chromatin remodeling at the Th2 cytokine gene loci. J Biol Chem 279: 26983-26990.

38. Jury EC, Isenberg DA, Mauri C, Ehrenstein MR (2006) Atorvastatin restores Lck expression and lipid raft-associated signaling in $\mathrm{T}$ cells from patients with systemic lupus erythematosus. J Immunol 177: 7416-7422.

39. Surls J, Nazarov-Stoica C, Kehl M, Olsen C, Casares S, et al. (2012) Increased membrane cholesterol in lymphocytes diverts T-cells toward an inflammatory response. PloS One 7: e38733.

40. Griesenauer B, Paczesny S (2018) Less cholesterol means better tumor killing for cytotoxic T9 cells. Rockefeller University Press.

41. Zeiser R (2018) Immune modulatory effects of statins. Immunology 154: 69-75.

42. Ghittoni R, Enea Lazzerini P, Laghi Pasini F, Baldari CT (2007) T lymphocytes as targets of statins: molecular mechanisms and therapeutic perspectives. Inflamm Allergy Drug Targets 6: 3-16.

43. Shimada K, Park JK, Daida H (2006) T helper 1/T helper 2 balance and HMG-CoA reductase inhibitors in acute coronary syndrome: statins as immunomodulatory agents?. Oxford University Press 2006: 2916-1918.

44. Kwak B, Mulhaupt F, Myit S, Mach F (2000) Statins as a newly recognized type of immunomodulator. Nat Med 6: 1399.

45. Weber MS, Prod'homme T, Youssef S, Dunn SE, Steinman L, et al. (2014) Neither T-helper type 2 nor Foxp3+ regulatory $\mathrm{T}$ cells are necessary for therapeutic benefit of atorvastatin in treatment of central nervous system autoimmunity. J Neuroinflammation 11: 29.

46. Link A, Ayadhi T, Böhm M, Nickenig G (2006) Rapid immunomodulation by rosuvastatin in patients with acute coronary syndrome. Eur Heart J 27: 2945-2955.

47. Dunn SE, Youssef S, Goldstein MJ, Prod'homme T, Weber MS, et al. (2006) Isoprenoids determine $T h 1 / T h 2$ fate in pathogenic $T$ cells, providing a mechanism of modulation of autoimmunity by atorvastatin. J Exp Med 203: 401-412.

48. Peng X, Jin J, Giri S, Montes M, Sujkowski D, et al. (2006) Immunomodulatory effects of 3-hydroxy-3-methylglutaryl coenzyme-A reductase inhibitors, potential therapy for relapsing remitting multiple sclerosis. J Neuroimmunol 178: 130-139.

49. Jiang T, Zhou C, Ren S (2016) Role of IL-2 in cancer immunotherapy. Oncoimmunology 5: e1163462.

50. Dunn GP, Koebel CM, Schreiber RD (2006) Interferons, immunity and cancer immunoediting. Nat Rev Immunol 6: 836.

51. Szabo SJ, Sullivan BM, Peng SL, Glimcher LH (2003) Molecular mechanisms regulating Th1 immune responses. Annu Rev Immunol 21: 713-758.

52. Vigneron $\mathrm{N}$ (2015) Human tumor antigens and cancer immunotherapy Biomed Res Int 2015: 948501.

53. Waters JP, Pober JS, Bradley JR (2013) Tumour necrosis factor and cancer. J Pathol 230: 241-248.

54. Zheng L, Bidere N, Staudt D, Cubre A, Orenstein J, et al. (2006) Competitive control of independent programs of tumor necrosis factor receptor-induced cell death by TRADD and RIP1. Mol Cell Biol 26: 3505-3513.

55. Hirano T (1992) The biology of interleukin-6. InInterleukins: Molecular Biology and Immunology. Karger Publishers 51: 153-180.

56. Kishimoto T, Tanaka $\mathrm{T}$ (2015) Interleukin 6. Encyclopedia of Inflammatory Diseases 2015: 1-8.

57. Takatsu K, Kouro T, Nagai Y (2009) Interleukin 5 in the link between the innate and acquired immune response. Adv Immunol 101: 191-236.

58. Kraakman MJ, Dragoljevic D, Kammoun HL, Murphy AJ (2016) Is the risk of cardiovascular disease altered with antiinflammatory therapies? Insights from rheumatoid arthritis. Clin Transl Immunology 5: e84.

59. Proto JD, Doran AC, Subramanian M, Wang H, Zhang M, et al. (2018) Hypercholesterolemia induces $\mathrm{T}$ cell expansion in humanized immune mice. The Journal of Clinical Investigation 128.

60. Mailer RK, Gisterå A, Polyzos KA, Ketelhuth DF, Hansson GK (2017) Hypercholesterolemia induces differentiation of regulatory $\mathrm{T}$ cells in the liver. Circ Res 2017: CIRCRESAHA-116.

61. Molnár E, Swamy M, Holzer M, Beck-García K, Worch R, et al. (2012) Cholesterol and sphingomyelin drive ligand-independent T-cell antigen receptor nanoclustering. J Biol Chem 287: 42664-42674.

62. Guo X, Yan C, Li H, Huang W, Shi X, et al. (2017) Lipid-dependent conformational dynamics underlie the functional versatility of T-cell receptor. Cell Res 27: 505.

63. Blank N, Schiller M, Krienke S, Busse F, Schätz B, et al. (2007) Atorvastatin inhibits $\mathrm{T}$ cell activation through 3-hydroxy-3methylglutaryl coenzyme A reductase without decreasing cholesterol synthesis. J Immunol 179: 3613-3621.

64. Wu LH, Wan YL, Xie HY, Zhang WJ, Zheng SS (2004) Immunosuppression in human peripheral blood $\mathrm{T}$ lymphocytes by fluvastatin. Acta Biochim Biophys Sin 36: 649-655.

65. Kanda H, Yokota K, Kohno C, Sawada T, Sato K, et al. (2007) Effects of low-dosage simvastatin on rheumatoid arthritis through reduction of Th1/Th2 and CD4/CD8 ratios. Mod Rheumatol 17: 364-368.

66. McBride JA, Striker R (2017) Imbalance in the game of T cells: What can the CD4/CD8 T-cell ratio tell us about HIV and health?. PLoS Pathog 13: e1006624. 